\title{
Comparison of the Efficacy of Three Different Mouthrinse Solutions in Decreasing the Level of Streptococcus Mutans in Saliva
}

\author{
Mustafa Murat Kocak \\ Suat Ozcan ${ }^{b}$ \\ Sibel Kocak ${ }^{b}$ \\ Ozgur Topuzc \\ Hulya Erten ${ }^{d}$
}

\section{ABSTRACT}

Objectives: The aim of this study was to evaluate the effectiveness of three different antiseptic mouthrinse solutions on the saliva samples obtained from the individuals, who had high caries activity rate.

Methods: The efficacy of three antiseptic mouthrinses were evaluated in a study with healthy volunteers. The three antiseptic solutions used in this study were $0.1 \%$ octenidine dihydrochloride (Octenisept, Schülke\&Mayr, UK), 0.12\% chlorhexidine digluconate (Kloroben, Drogsan, Turkey) and an antimicrobial enzymatic rinse (Biotene, Laclede,Inc, USA). A total of 27 adult volunteer subjects were participated in the study. The subjects were stratified into three balanced group. Then the mouth rinses were used by each group according to the manufacturer's directions. The subjects were restricted for 60 minutes for food intake after using the prescribed mouthrinse. The saliva samples were collected from the volunteers at 1, 10 and 60 minutes after their usage in tubes. The tubes were kept in $+4^{\circ} \mathrm{C}$ in a fridge till the evaluation. $10^{-3}$ and $10^{-5}$ dilutions were prepared for each solution and S. mutans were evaluated according to total number of colony forming unit (CFU) per $\mathrm{ml}$. The dilutions were spreaded on the surface of Brucella agar plates for anaerobic incubation for 48 hours. The dilutions were $100,10^{-3}$ and $10^{-5}$ of the solutions Kloroben, Biotene, Octenisept, and the time factor were $0,1,10$ and 60 minutes. The statistical analyses were performed by Duncan and Bonferroni tests.

Results: Octenisept was found to be more effective over $S$. mutans than the other mouthrinse solutions $(P<.05)$.

Conclusions: All mouthrinse solutions except Biotene were effective on oral microorganisms. (Eur J Dent 2009;3:57-61)

Key words: Mouthrinse solutions; Saliva; S. mutans.

\footnotetext{
a DDS, PhD, Private Practice, Ankara, Turkey,

b PhD, Department of Operative Dentistry and Endodontics, Faculty of Dentistry, University of Gazi, Ankara, Turkey.

c DDS, PhD, Department of Operative Dentistry and Endodontics, Faculty of Dentistry, University of Gazi, Ankara, Turkey.
}

${ }^{d}$ DDS, Phd, Professor, Department of Operative Dentistry and Endodontics, Faculty of Dentistry, University of Gazi, Ankara, Turkey.

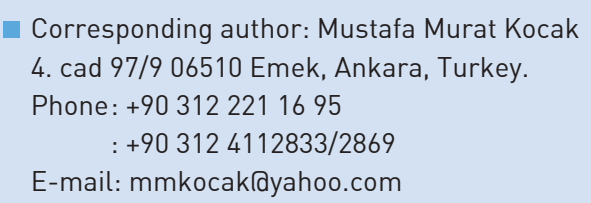

E-mail: mmkocakayahoo.com 


\section{INTRODUCTION}

Antiseptic mouth rinse solutions are used in many clinical situations for different prophylactic and therapeutic purposes. It is difficult to decide which product is suitable for a particular purpose because of the variations of the antimicrobial efficacy and kinetics of the solutions." The main indications are either the improvement of dental health (plaque and gingivitis elimination in particularl or the prevention of infections caused by bacteria of the oral cavity in specific situations such as tooth extraction, intraoral surgical procedures or immuno suppression due to cancer therapy or transplantation. ${ }^{2,3}$ The use of antimicrobial mouth rinses has been proposed as a means of reducing the levels of oral bacteria, specifically Streptococcus mutans (S.mutans). ${ }^{4}$

Chlorhexidine is a broad-spectrum antimicrobial agent. In dentistry, chlorhexidine has been used to reduce the level of oral $S$. mutans, and incorporated into mouth rinse solutions. Chlorhexidine was shown to inhibit plaque formation, also reduce gingival inflammation and prevent dental caries. ${ }^{5}$ However, studies aimed at reducing the levels of $S$. mutans in the oral cavity with chlorhexidine had reported large variations, inconsistencies, and an inability to ablate $S$. mutans. ${ }^{6}$

Octenidine dihydrochloride was developed at the Sterling Winthrop Research Institute as a potential topical antimicrobial agent. ' In a previous study this compound was found to be effective in inhibiting the growth of plaque forming bacteria ${ }^{8,9}$ and in reducing the development of plaque in experimental animals. ${ }^{10}$

Biotene Mouthwash (Laclede ,CA,USA) is especially beneficial to individuals experiencing dry mouth or having oral irritations. The strength of the Biotene products lies in their ingredients: they contain antibacterial enzymes which found naturally in human saliva. Biotene contains three primary enzymes-Glucose Oxidase, Lactoperoxidase, and Lysozyme, which are carefully balanced for a special function in boosting and replenishing saliva's own defenses. These ingredients' antibacterial and healing properties create a natural oral protection. ${ }^{11}$

The aim of this study was to evaluate the effectiveness of three different antiseptic mouth rinses on the saliva samples of individuals, who had high caries activity rate.

\section{MATERIALS AND METHODS}

A total of twenty-seven, fourteen male and thirteen female, healthy volunteers aged between 20-22 were included in the study. The participants had at least four restored teeth in their mouth but without any decay or tooth lose. Antibiotic or other medication consumption in the last two months that might interfere oral hygiene and participants with periodontal problems and the ones who were taking special diet were excluded from the study. First, the medical stories of the volunteers were taken and they were requested to sign a consent form, afterwards all of them received professional tooth cleaning. Then a participant number was given for each and randomly divided into three equal groups. The volunteers In Group 1, rinsed with Octenisept (Octenidine dihydrochloride), in Group 2 with Kloroben (Chlorhexidine digluconate) and in Group 3 with Biotene. The groups rinsed for two minutes with the mouth rinses (Table 1) according to the manufacturers' instructions. The saliva samples were collected with sterile tubes

Table 1. Mouth rinse solutions.

\begin{tabular}{|c|c|c|}
\hline Product & Listed ingredients & Manufacturer \\
\hline Octenisept & $\begin{array}{l}\% 0.1 \text { Octenidine dihydrochloride } \\
\begin{array}{ll}\% 2 & \text { 2-Phenoxyethanol }\end{array}\end{array}$ & $\begin{array}{l}\text { Schülke\&Mayr } \\
\text { Sheffield, UK }\end{array}$ \\
\hline Kloroben & $\begin{array}{c}\% 0.12 \text { Chlorhexidine digluconate } \\
\% 0.15 \text { Benzidamin } \mathrm{HCl}\end{array}$ & $\begin{array}{c}\text { Drogsan } \\
\text { Ankara, Turkey }\end{array}$ \\
\hline Biotene & $\begin{array}{l}\text { Enzyme system, distilled sterile water, Propylene Glycol, } \\
\text { Xylitol, Sodiumbenzoat, Benzoic acid, Aloe vera, Calcium } \\
\text { lactate, Potasium tiocionate }\end{array}$ & $\begin{array}{l}\text { Laclede Inc. } \\
\text { CA, USA }\end{array}$ \\
\hline
\end{tabular}


at the 1, 10 and 60 minutes following the rinsing procedure. The tubes were kept in $+4^{\circ} \mathrm{C}$ in a fridge till the evaluation. The solutions were diluted with distilled water. The dilutions were spreaded on the surface of Brucella agar plates for anaerobic incubation for 48 hours. The dilutions were 100 , $10^{-3}$ and $10^{-5}$ of the solutions Kloroben, Biotene, Octenisept, and the time factor were 0, 1, 10 and 60 minutes. S. mutans were evaluated according to total number of colony forming unit (CFU) per $\mathrm{ml}$.

The data were collected and statistical analysis were performed by Duncan and Benferroni tests. Also factorial repeated ANOVA was used for numerical evaluation of bacteria.

\section{RESULTS}

There were no $S$. mutans growth in Octenisept group at 1 and 10 minute calculations for all dilution levels $\left(100,10^{-3}\right.$ and $\left.10^{-5}\right)$, but bacterial growth was observed only in one specimen at 60 minute group and when compared with the initial values a statistically significant difference was found $(P<.05)$. In Kloroben group for all dilution levels $\left(100,10^{-3}\right.$ and $\left.10^{-5}\right)$ at 1 and 10 minute calculations there was a significant reduction in $S$. mutans amount when compared with the initial values and this reduction was also statistically significant $(P<.05)$. At the 60 minute calculations of the same group, no significant difference was found $(P<.05)$. In Biotene group, for all dilution levels and time periods (for 1, 10 and 60 minutes calculations) no statistically significant difference was found $(P<.05)$.

In Table 2 the mean differences and the standart deviations of the rinsing solutions were given in latin letters. No differences were found between the groups stated with the same letters, but the statistical differences are clear between the groups stated with different letters.

Table 2. Statistical results of the mouth rinse solutions.

\begin{tabular}{lc}
\hline Solutions & $\mathrm{x} \pm \mathrm{Sx}$ \\
\hline Kloroben & $2.33 \pm 0.107 \mathrm{~A}$ \\
Biotene & $2.67 \pm 0.871 \mathrm{~A}$ \\
Octenisept & $1.00 \pm 0.261 \mathrm{~B}$ \\
\hline
\end{tabular}

$(P<.05)$

\section{DISCUSSION}

The oral cavity represents a dynamic ecosystem therefore it would not be totally advantageous to eliminate all elements of the oral microflora in an effort to control dental plaque-associated infections. Rather, it may be more ideal to remove only most cariogenic and periodontopathic elements of the dental plaque microflora while permitting the more innocuous elements to remain. ${ }^{8}$

A relatively large number of chemical agents, which are mostly synthetic compounds, have been used for many purposes, control of dental plaque, elimination of oral pathogens, against malodor, etc. ${ }^{12}$

The presented study was designed for the evaluation of the antimicrobial effects of a new solution containing octenidine dihydrochloride (Octenisept), a chlorhexidine-based product (Kloroben) and a mouth rinse which contains natural antimicrobial enzymes (Biotene) on the the levels of $S$. mutans in saliva.

Octenidine dihydrochloride (OCT) was originally developed as a potential broadspectrum topical antimicrobial agent ${ }^{13}$ and used as an oral rinse is reported to inhibit dental plaque and caries in rats, ${ }^{14}$ dental plaque in-primates ${ }^{15}$ and in humans. ${ }^{16}$ One of the recent studies showed that a $0.1 \%$ octenidine mouth rinse provided statistically significant reductions of $39 \%$ less plaque, $50 \%$ less gingivitis, and $60 \%$ fewer gingival bleeding sites. ${ }^{17}$ In this study, it was observed that Octenisept had a significant effect on $S$. mutans and preserved antimicrobial efficiancy even after 60 minutes.

Chlorhexidine ( $\mathrm{CHX}$ ) digluconate has a 30 year history in dental medicine. ${ }^{18}$ It is the most throughly studied and the most effective antiplaque and anti-gingivitis agent known today. ${ }^{19}$ Gjermo et $\mathrm{al}^{20}$ reported that rinsing twice a day with $10 \mathrm{ml}$ of a $0.2 \% \mathrm{CHX}$ inhibited the dental plaque formation. Furthermore, its antigingivitis efficacy was also well documented.2123 Unfortunately, these positive effects are accompanied by side effects, the most disturbing being extrinsic tooth staining. ${ }^{24-27}$ In few cases, the occurrence of gingival desquamation and painful mucosa were reported. ${ }^{23,25}$

In our study, Kloroben had significantly reduced the S.mutans levels in saliva samples. 
However, it was observed that its efficiency was lower than Octenisept in the $60^{\text {th }}$ minute. Also Robrish et al ${ }^{28}$ reported that OCT had a more persistent antimicrobial effect on the organisms in plaque than that obtained by $\mathrm{CHX}$. However, Dogan et $\mathrm{al}^{29}$ compared the short-term relative antibacterial effects of OCT and $\mathrm{CHX}$. Their results were similar with our study, OCT was found favorably more effective than $\mathrm{CHX}$ in its antibacterial activity, both in vitro and in vivo. Although the initial antimicrobial activities of OCT and $\mathrm{CHX}$ are comparable, as a result of its better persistant antimicrobial activity we may suggest that OCT have promising effeciency on S.mutans as a mouth rinse solution.

Although the results showed that Biotene had no effects on salivary $S$. mutans levels, further studies are required to observe the effects of the solution on the oral flora and the oral cavity. ${ }^{30}$

\section{CONCLUSIONS}

The finding of the present study suggest that OCT and $\mathrm{CHX}$ mouthrinses are extremely effective in reducing $S$. mutans levels in saliva. As a result, the data presented in this study allows classification of different mouthrinse solutions due to their efficacy in decreasing the levels of $S$. mutans in saliva and enable the prescribing dentist or oral hygienist to make his choice based on antimicrobial impact.

\section{ACKNOWLEDGEMENT}

This study was presented at Turkish Society of Restorative Dentistry IVth International Congress which was held in Antalya, Turkey on 19-22 May 2005.

\section{REFERENCES}

1. Pitten FA, Kramer A. Antimicrobial efficacy of antiseptic mouth rinse solutions. Eur J Clin Pharmacol 1999;55:95100.

2. Cannell JS. The use of antimicrobials in the mouth. $J$ Int Med Res 1981;9:277-282.

3. Ciancio S. Expanded and future uses of mouth rinses. $J A m$ Dent Assoc 1994;125:29-32.

4. Menendez A, Li F, Michalek SM, Kirk K, Makhija SK, Childers NK. Comparative analysis of the antibacterial effects of combined mouth rinses on Streptococcus mutans. Oral Microbiol Immunol 2005;20:31-34.

5. Fardal 0, Turnbull RS. A review of the literature on use of chlorhexidine in dentistry. J Am Dent Assoc 1986;112:863869.

6. Hatta H, Tsuda K, Ozeki M. Passive immunization against dental plaque formation in humans: effect of a mouth rinse containing egg yolk antibodies (IgY) specific to Streptococcus mutans. Caries Res 1997;31:268-274.

7. Bailey DM, De Grazia CG, Hoff SJ. Bispyridinamines: a new class of topical antimicrobial agents as inhibitors of dental plaque. J Med Chem 1984;27:1457-1464.

8. Slee AM, O'Connor JR. In vitro antiplaque activity of octenidine dihydrochloride (WIN 41464-2) against preformed plaques of selected oral plaque-forming microorganizms. Antimicrob Agents Chemother 1983;23:379384.

9. Slee AM, O'Connor JR, Bailey DM. Relationship between structure and antiplaque and antimicrobial activities for a series of bispyridines. Antimicrob Agents Chemother 1983;23:531-535.

10. Emilson CG, Bowen WH, Robrish SA, Kemp CW. Effect of the antibacterial agents octenidine and chlorhexidine on the plaque flora in primates. Scand J Dent Res 1981;89:384392.

11. http://www.laclede.com/products/mouthwash.asp.

12. Özan F, Sümer Z, Polat ZA, Er K, Özan Ü, Deḡer O. Effect of mouthrinse containing propolis on oral microorganisms and human gingival fibroblasts. Eur J Dent 2007;1:195-201.

13. Sedlock DM, Bailey DM. Microbicidal activity of octenidine hydrochloride, a new alkanediylbis[pyridine] germicidal agent. Antimicrob Agents Chemother 1985;28:786-790.

14. Shern RJ, Monnel-Torrens E, Bowen WH, Kingman A. Effects of two recently developed antiseptics on dental plaque and caries in rats. AADR Prog \& Abst 1980;59:186.

15. Emilson CG, Bowen WH, Robrish SA, Kemp CW. Effect of the antibacterial agents octenidine and chlorhexidine on the plaque flora in primates. Scand J Dent Res 1981;89:384392.

16. Patters MR, Anerud K, Trummel CL, Kornman KS, Nalbandian J, Robertson PB. Inhibition of plaque formation in humans by octenidine mouth rinse. $J$ Periodontal Res 1983;18:212-219.

17. Beiswanger BB, Mallatt ME, Mau MS, Jackson RD, Hennon DK. The clinical effects of a mouth rinse containing $0.1 \%$ octenidine. J Dent Res 1990;69:454-457.

18. Löe H, Schiött CR. The effect of mouth rinses and topical application of chlorhexidine on the development of dental plaque and gingivitis in man. J Periodontal Res 1970;5:7983. 
19. Hoffmann T, Bruhn G, Richter S, Netuschil L, Brecx M. Clinical controlled study on plaque and gingivitis reduction under long-term use of low-dose chlorhexidine solutions in a population exhibiting good oral hygiene. Clin Oral Investig 2001;5:89-95.

20. Gjermo P, Rolla G, Arskaug L. Effect on dental plaque formation and some in vitro properties of 12 bis-biguanides. J Periodontal Res Suppl 1973;12:81-92.

21. Addy M. Chlorhexidine compared with other locally delivered antimicrobials. J Clin Periodontol 1986;13:957964.

22. A critical review and appraisal of the published literature relating to the oral use of chlorhexidine in dentistry. PhD thesis, Cardiff Dental School, University of Wales, Heath Park.

23. Lang NP, Brecx M. Chlorhexidine digluconate. An agent for chemical plaque control and prevention of gingival inflammation. J Periodontal Res 1986;21:74-89.

24. Eriksen HM, Nordbo H, Kantanen H, Ellingsen JE. Chemical plaque control and extrinsic tooth discoloration. A review of possible mechanisms. J Clin Periodontol 1985;12:345-350.

25. Flotra L, Gjermo P, Rolla G, Waerhaug J. Side effects of chlorhexidine mouth washes. Scand J Dent Res 1971;79:119125.

26. Lang NP, Hotz P, Graf H, Geering AH, Saxer UP, Sturzenberger OP, Meckel AH. Effects of supervised chlorhexidine mouth rinses in children. A longitudinal clinical trial. J Periodontal Res 1982;17:101-111.

27. Lang NP, Hase JC, Grassi M, et al. Plaque formation and gingivitis after supervised mouth rinsing with $0.2 \%$ delmopinol hydrochloride, $0.2 \%$ chlorhexidine digluconate and placebo for 6 months. Oral Dis 1998;4:105-113.

28. Robrish SA, Emilson CG, Kemp CW, Eberlein D, Bowen WH. A comparison of viable counts and adenine nucleotide analysis to determine the effect of antimicrobial agent on dental plaque. Curr Microbiol 1981;5:343-347.

29. Dogan AA, Adiloglu AK, Onal S, Cetin ES, Polat E, Uskun E, Koksal F. Short-term relative antibacterial effect of octenidine dihydrochloride on the oral microflora in orthodontically treated patients. Int J Infect Dis 2008;12:e19e25.

30. Lehane RJ, Murray PA, Deasy MJ. Effect of an enzymatic rinse on salivary levels of Streptococcus mutans and lactobacilli in periodontally treated patients. Periodontal Clin Investig 1997;19:17-21. 